\title{
Sibling Care Giving Experiences among the Rural NSO Children of Cameroon
}

\author{
Lilian F. Wiysahnyuy*, Ph.D \\ Higher Teacher Training College, University of Bamenda, Cameroon \\ *Corresponding Author: Lilian F. Wiysahnyuy, Ph.D, Higher Teacher Training College, University of \\ Bamenda, Cameroon
}

\begin{abstract}
Childrearing is a complex phenomenon which engages different stakeholders and involves divergent activities, one of which is sibling care giving. Among the rural Nso of Cameroon, it is a common practice for parents to leave their younger children with their elder siblings as they set out for some outdoor activities. This research was designed to explore the activities that characterize sibling care giving and assess the extent to which such routine, conscious and unconscious tasks equip the sibling caregivers with skills that could enable them adapt and exploit the opportunities in their environment. The Sample of the study comprised 50 caregivers of 7-11years old and 50 parents selected using the convenient and purposive sampling techniques from Kishong a rural enclave of Nso, a principal chiefdom of the Cameroon Grasslands. The instruments used for data collection were; observations check list, an interview guide, and informal conversations. A digital camera was used to record some of the activities carried out by sibling caregivers. The data was analysed using thematic analysis. From the basis of this, the findings revealed that sibling care giving in Nso culture is the preserve of boys and girls at the early stage of development (5-7years old) but it inclines to the female children at the later stage of development (8-11years old). The findings also revealed that some of the activities that characterized sibling care giving in rural Nso are food preparation, feeding, toilet training, laundry, lulling the younger sibling to sleep, supervision and monitoring of the younger siblings as they carry out their household chores and school assignments. It was realised that the act of care giving enhances the caregivers' divergent thinking, socialisation, leadership skills and specially trains and prepare young girls for motherhood. In as much as it is necessary to train older siblings to take care of their younger ones, parents should create time to monitor the care giving activities in order to ensure the general wellbeing of their children and to maintain the emotional tie with them.
\end{abstract}

Keywords: Care Giving, Caregiver, Sibling, Tasks, Nso Culture And Experiences.

\section{INTRODUCTION}

Sibling care giving is one of the main aspects that characterize child rearing practices across cultures. Most families in rural areas use their older children (5-11years old) to take care of their younger ones at an early age. As such they are treated as sibling caregivers since their parents are occupied with other activities for the welfare of the family. According to Griffiths \& Unger, (1994) and Pruchno, Patrick, \& Burant, (1996), older siblings are a valuable family resource throughout the lifespan because they act as companions and resources to the younger siblings and will most likely replace the parents as primary caregivers to these younger siblings in the future. According to Mweru (2011), sibling care giving means leaving young children under the care of their older siblings. Sibling care giving in most parts of Cameroon is prevalent in rural areas and low income urban settings. This is because the parents in these environments do not have enough income to employ nannies or take the children to day care centers. Sibling care giving involves multifaceted activities which may differ from one context to another. Therefore this research aimed at exploring the activities carried out by older siblings when taking care of their younger ones and also to assess the extent to which these tasks equip the sibling caregivers and the younger siblings with skills that could enable them to adapt and exploit the opportunities in their environment.

\subsection{Research Questions}

- What are the activities that characterize sibling care giving among the Nso children in Kishong village?

- How do these activities enhance skill development of the caregivers and the younger siblings? 


\subsection{Review of Related Literature}

Sibling care giving is perceived by different writers from diverse perspectives. Evans (1994) emphasizes that in many cultures of developing countries children may be given the role of caregivers for younger siblings at an early stage. Best (2013) also opines that most African parents delegate the care of younger siblings to girls and boys of 6-10 years old. This means that when parents are going out they assign the older siblings to look after the younger ones. Sibling care giving among other things include: toilet training, feeding, cleaning and ensuring security. An example of toilet training is seen among the Gusii of Kenya where the older siblings dig holes for the younger ones to use (Mweru, 2009). Mweru (2011), states that "more girls seem to be assigned the role of caring for younger children in Kenya. Perhaps this is due to the fact that taking care of young children in Kenya has long been considered as women's work." From this premise it is apparent that girls are trusted to take better care of their younger ones than boys. The act of assigning mostly girls to take care of their younger sibling indicates the need for training to be oriented towards the need of future mothers. Girls are considered as alternative mothers to the children they are taking care of. This shows that parents do not only assign their children to tasks of care giving because they want the children to help them but to train them to take up future responsibilities with ease. Lancy (1996) intimates that, from 5 years-old, girls start tending their younger ones there by preparing themselves to become future mothers. Litwin, stoeckel, \& Roll (2014) also lay emphasis on the fact that parents use their older children as primary caregivers to prepare them for future family life. These children take care of their siblings feeding, clean them especially when they defecate or urinate on themselves, and also lull them to sleep.

According to Griffiths \& Unger, (1994) and Pruchno, Patrick, \& Burant, (1996), sibling care giving activities are carried out by both boys and girls; but older girls are better teachers and nurturers as they spend more time playing, feeding, cleaning their younger ones while the boys are better moderators. Sibling care giving is carried out along with other household chores. This at times is very stressful but the older siblings enjoy doing it because caring for their siblings is associated with less stress (Penning and $\mathrm{Wu}, 2015)$. In effect, the parents of the care givers are mainly preparing or initiating them into the male or female society (Nsamenang ,2005). Also, carrying out adult duties is preparing the sibling caregivers toward a positive and productive future so that they will not find it difficult to handle their homes. Doing this create a strong bond between the child and the care giver which make the child to be more attach to their sibling who is the primary caregiver than the parents.

According to Kramer \& Conger, (2009), siblings share a common and unique bond that is further cemented by the amount of time spent with one another, understanding of a similar place in the family structure, and the complex manner in which they have an effect on one another's lives. These factors play an important role in the manner in which siblings are socialized and how they feel about their participation in their family structures. Siblings are sometimes eager to demonstrate their own abilities and uniqueness in light of the accomplishments of the elder siblings. This can be seen in their personal goal setting and the manner in which they choose to demonstrate their own abilities. Equally, Africa has a long standing cultural tradition of providing care to family members especially the younger ones which may affect the degree to which they experience family care giving (Dilworth Anderson et al, 2005). As a result when parents allow their young children with the older siblings, they show more positive attitude toward their younger siblings and greater interest in providing support for them (Gold, 1990). This is because they understand that their younger ones are smaller, weaker and less knowledgeable as compared to them. Kramer \& Conger (2009) reiterates that when parents are dealing with challenges that may render them less available, they are more dependent upon older siblings for support. Older children learn to provide essential caretaking functions in the absence of their parents, and younger children learn to depend on the elder siblings for some of the functions previously provided by their parents.

The act of sibling care giving enhances attachment between the child and the caregiver. According to Bowlby (1988), children develop strong emotional ties towards their primary caregivers. The fact that the elder sibling look after the younger ones by feeding them, playing with them, protecting them from danger, lulling them to sleep, carrying them on their backs and also cleaning them, makes the younger siblings to develop more love for them than any other person. The attachment theory of Bowlby $(1969,1988)$ "suggests that an infant's primary caregiver serves as a secure base from which he or she can explore the world as well as a safe haven when the infant experiences distress and the 
attachment behaviour system is activated." This emotional bond leads to the development of trust towards the caregiver since they are always with them (Erikson, 1968). This attachment is fully expressed when children cry or turn away at any attempt to be taken off from their caregivers.

The works of Mweru (2009 \& 2011) show that sibling care giving in Kenya is mostly carried out in rural areas and in low-income urban areas. This is because most of the parents in the rural settings do not have the means to employ housemaids to take care of their children that is why they prefer to keep them with older siblings. On the other hand, in urban settings child care is handled differently. In most cases use is made of day cares, housemaids, nannies and child nurses. According to Durojaiye (1976), educated urban mothers prefer to employ housemaids to take care of their children because they do not have time to do it. From this presentation of different practices in child care, it is apparent that sibling care giving is mostly carried out in rural settings although the activities may differ from one context to the other. It has been realised that little or nothing is documented on sibling care activities in kishong. Based on this premise, the paper seeks to explore some of the activities that characterized sibling care among the Nso children of Kishong village.

\section{Methods ANd Procedures}

This study was largely qualitative in nature. It employed an exploratory design. It was designed to explore in-depth qualitative data on the activities carried out by the sibling caregivers in the Cameroon Grasslands village of Kishong in Nso. The Sample of the study comprised 50 Caregivers of 7-11years old who were taking care of 72 children, and 50 female parents selected using the convenient and purposive sampling techniques. I decided to use 50 household because I realized that all the households had sibling caregivers. As far as parents were concerned, I chose the parents of the sibling caregivers who participated in the study so as to compliment the information gotten from the caregivers.

The instruments used for data collection were; observations check list, an unstructured interview guide, and informal conversations. Before administering the instruments, consent was sought from the participants. Since the sibling caregivers were considered as minors consent was sought from their parents. The observations check list was designed basically to help me observe the activities of the care givers and informal conversations were used during the observation sessions. Although the observation was non participants in nature, there were certain moments that I had to converse with the caregivers to understand why they carried out certain activities. This was in a bid to collect more information which could not be gotten through observations. All the 50 sibling caregivers were observed within a period of 20 days at their various homes. A digital camera was used to record some of the activities carried out in the course of sibling care giving. This research was carried out during the summer holiday which made it very easy for me to meet the caregivers at home. The interview guide was designed specifically for parents, which aimed at finding out why they assigned older children to take care of their younger ones. The interviews took place on two main traditional days, "Kilovee" and "Ngolum", respected by all the Nso. A week in Nso is made of eight days and these two days are set aside for cultural rites and by default are traditional public holidays in Nso. On these days, farm work, the principal activity of the people is forbidden. Therefore I used this opportunity to meet the parents at home. Data was analyzed using thematic analysis. Since the work was qualitative in nature, data was grouped under various themes which were mainly on the activities carried out by the caregivers.

\section{FINDINGS}

From the observation, informal conversation and interviews with the caregivers and parents, it was realized that sibling care in Kishong is carried out by female and male children but it gradually becomes the activity of the female children as they mature. Specifically, $80 \%$ of the children who were involved in sibling care giving were females. Some parents advanced reasons for assigning mostly girls as caregivers. Majority were of the opinion that they preferred girls to boys because the activity was meant to train girls for their future responsibilities as mothers. One of the informants reported as follows:

My two children are always taken care of by their elder sister who is 10 years old. When I am going out of the house I do not bother because I know that she will take good care of them. In the morning, especially during the week, she prepares the children for school. She carries the younger one who is in nursery school on her back and drops her before going to her own school. After school she washes 
their uniforms and their shoes in preparation for the next day. She also gives them food when they are hungry and makes sure they do not go far off from the compound. All these activities are meant to prepare her for motherhood and marriage.

Another parent said:

I always keep my child who is one year old with my eldest daughter who is nine years old. She is the one who mostly prepares the baby's food and washes his clothes on Saturdays. She enjoys taking care of her brother. At times she carries him on the back and performs other household tasks. She plays with him and lulls him to sleep. When he is dirty she changes his clothes. I assign her to do all these things because I know in future she will become a mother and will carry out the same tasks without any problem.

From these responses and others it was confirmed that most parents assign care giving to girls to train them for future responsibilities as earlier stated. Although most parents in Kishong assigned care giving to specific children, it was also observed that some parents kept their children to play with other children in the compound without necessarily assigning a particular child to take care of them (see figure 1). Some of these young children imitated the older children in carrying out other domestic chores like laundry and fetching of water. When asked why they did not assign any person to take care of those children, most of the parents said that they believed the children could take care of themselves and that the older children were there to take care of security issues. This was mostly seen in polygamous compounds. What caught my interest most was the fact that the children knew where to get their food whenever they were hungry and some shared their food with others. This culture is important as it is to provide care to the younger children, it is a social niche which in form and orientation resembles the daycares centres that are characteristics of urban milieus.

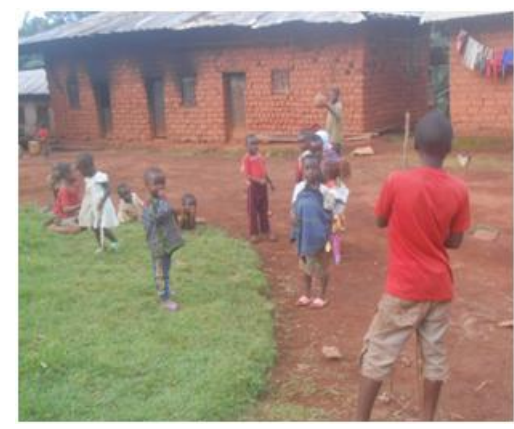

Figure1. Children in one of the village head's compound left by parents to play with older ones

The children were between 2 to 11 years. Although of different ages, they all shared the fun of playing together and the older ones ensured the security of the younger ones.

\subsection{Activities of Sibling Care Giving}

It was captured that sibling care giving entailed a lot of activities. Some of these activities were food preparation and feeding, toilet training, laundry, bathing, lulling the children to sleep, teaching and supervision.

Food preparation and feeding: Food preparation and feeding were some of the key elements of sibling care observed among the Nso children in Kishong. In some household it was realized that parents prepared food and kept for the children before going out of the house. In this case the caregivers fed the children at the appropriate time. It was discovered that the sibling caregivers were very conscious of time as far as feeding of their younger ones was concerned. In other houses the parents left the house without preparing the food meaning the caregivers had to prepare food for their younger siblings. Some older siblings were observed peeling potatoes which they had to cook for the younger ones. (See fig: 2) According to these girls they were already used to the tasks of preparing food for their younger siblings. One of them stated thus:

My mother does not prepare food for my younger brother before going to the farm, I am the one who does it. At times she tells me what to cook at times she does not. So I have to use my initiative to prepare something for my brother. Though at times the activities coupled with other chores are strenuous, I enjoy taking care of my brother. Whenever he is hungry he calls my name even when my mother is around. 
Parents were also asked why they often left the house without preparing food for their infants. The response from most of them was that the elder siblings knew what/how to prepare for the younger ones at the appropriate time.

Laundry: From the observation and interviews, it was realized that sibling caregivers also carried out laundry. Majority (85\%) of the sibling caregivers were the ones washing the clothes, shoes and the under wears of their younger siblings. Most of the caregivers did the laundry on Saturdays especially during school periods and on "Kilovee" and "Ngolum". From the informal conversation with one of the caregivers she said the following:

I wash the dresses of my younger sister every Saturday morning. There are times that I wash them twice a week. No other person in our house washes the dresses except of me. I love washing these dresses and I am used to this activity. My mother always tells me that she is training me so that in future I will take good care of my children and will always keep my house clean.

Toilet training: From the observation of the activities of the sibling caregivers, it was realized that sibling caregivers trained their young ones on how to use the toilet and what to say when they feel pressed. It was observed that some of the sibling caregivers dug tiny holes for their younger siblings to use, some used leaves, while others asked them to defecate on the ground and they carried with hoes, leaves or pieces of papers. It was equally observed that for children who were still too young and could not sit on their own, the caregivers provided a funnel through their laps for the child to defecate. It was realized that sibling caregivers used punishment to correct children who messed up themselves. At times they scolded them. This according to the caregivers was meant to make the younger siblings know that urinating or defecating on their bodies was a negative behaviour which had to be discouraged.

Lulling the younger sibling: This is one of the most important activities of care giving. Siblings lulled their younger ones to sleep mostly through the use of lullabies and mild dancing. Whenever it was time to sleep or to stop the child from crying, the caregiver would carry the child on the back and melody some lullabies for the child. Some of the lullabies which were song were "yo-o yo-o yo-o key, yo-o yo-o yo-o key, mati mami wiy fo kwa, komri kirung ke a wa yi. A lo yi la a for wanle". Meaning the child should stop crying and wait for the mother to come back from the farm and peel yams for her to eat. This lullaby was mostly to stop children from crying although it lulled most of them to sleep. Another lullaby was "Maareereng maareereng fo mbuuni se wan wor si. Shwaa wo kov, shwaa wo kov fo mbuuni se wan wor si." This lullaby was basically calling on some birds to make the child to sleep. When asked the importance of lullabies, one of the caregivers said, "Children easily fall asleep when a lullaby is being song and that is why I always sing when it is time for my brother to sleep. If I do not sing he will hardly sleep."

From the observations, the lullabies played the magic of cuddling children to sleep. It was noticed that children who listened to lullabies fell asleep easily than those whose caregivers never song any lullaby. According to the information gotten from the parents, it was realised that these lullabies were traditions handed down from generation to generations. Some of the parents referred to lullabies as the "magic songs" which could stop any child from crying or make them to sleep easily.

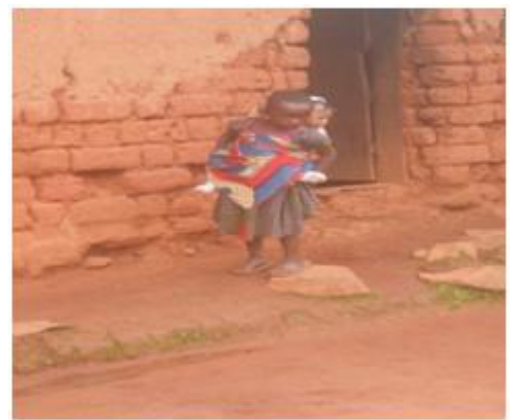

Figure2. A child of eight years old in Kishong carrying the younger sister, nine months old, on the back to lull her to sleep

Teaching and supervision of household chores: From the qualitative data collected, it was realised that the caregivers taught and supervised the younger ones to carry out household chores like sweeping, washing of utensils and dresses. They carried out these tasks with their younger siblings. At times the caregivers put water in a bucket and gave socks or pants to the younger ones to wash. All 
these enhanced the younger siblings' skills in washing and cleaning. When going to fetch water they also gave smaller containers to the younger siblings. Some taught the younger ones how to peel Irish potatoes and beans. Some of the caregivers were observed teaching their younger ones counting from number 1 to 10 and letters of the Nso and English alphabets. Some also supervised the school assignments given to their younger ones. Some of the caregivers were also observed teaching young children to be respectful, to always say sorry when they did something wrong and appreciate gifts from others. One of the informant was observed telling her younger sibling of three years old "when somebody gives you anything always say thank you and you should not eat without showing it to me or mummy." Another one asked the younger brother when I entered their house the following: "Didn't I tell you to always greet anybody that enters the house? Say welcome to auntie." All these helped the younger ones to be respectful and hospitable to others.

Play: The sibling caregivers also engaged in play activities with their younger siblings. Play activities among others included telephone line, family life, hide and seek, and cards. Some sibling caregivers as observed were involved in a type of play with the younger ones, where each person had to give names of boys and girls. These names were given in turns and each person that delayed in giving a name was disqualified from the game. The younger sibling of fours years old displayed a mastery of ten female and five male names within four minutes without any mistakes. These types of play enhanced cognitive skills like thinking and recalling.

Bathing: The findings from both parents and children revealed that more than $90 \%$ of the caregivers carried out this activity. They mostly bathed the children towards the evening periods and with warm water. It was realised that all the sibling caregivers observed bathing their younger ones used warm water most especially because of the climatic condition of the village which is always very chilly especially in the morning and evening hours.

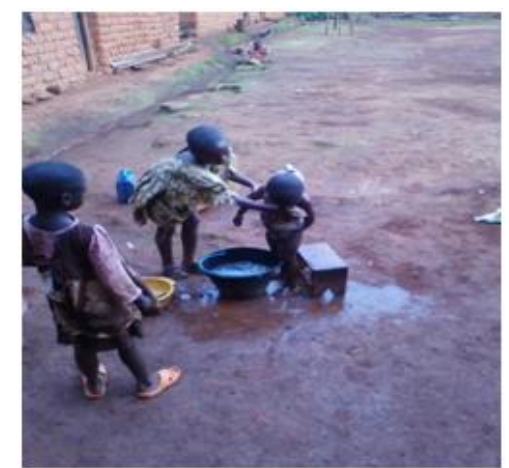

Figure3. An eight years old child in bathing her younger brother, three years old, while her sister of six years old watches on

\section{DISCUSSION}

Sibling care giving in Kishong village although observed across, the sex divide was more common with female children. Most parents emphasized their preference to assign such tasks to girls in order to train them to take up their future responsibilities as mothers. This is a positive aspect because when children start engaging in these activities at an early stage, they become used to them and would replicate the experiences when they attain parenthood. This fact aligns with Nsamenang (2005), who says that parents of the caregivers assign girls to sibling care mainly to prepare or initiate them into the female society. Mweru (2011) also emphasises that the role of caring for children in Kenya is based on the fact that taking care of children has long been considered as women's work. Therefore assigning girls as caregivers is an act of training them to become acquainted to it since that is what they have to do in future. This undoubtedly reflects broader gender-based responsibilities which cut across most cultures especially in community based Black African societies.

Sibling care giving among Nso kindred in Kishong entailed performing diverse activities like feeding the baby, changing of pants, bathing the baby, providing hygiene and sanitations assistance, clothing, cuddling, playing with and lulling to sleep. This shows that children who were involved in sibling care giving had a lot of responsibilities. The works of Klien, et al (2009) and (Mweru, 2009) can be used to support the experience of the Nso children but add that, to the plenitude of roles, sibling care ensures security to the younger ones. It was realized that the more the caregivers carried out these activities the more the younger siblings got closer to them there by developing a high level of trust 
towards the caregivers. This confirms Bowlby's (1988), attachment theory which states that children develop strong emotional tie towards their primary caregivers. The fact that the elder sibling look after the younger ones by feeding them, playing with them, protecting them from danger, lulling them to sleep, carrying them on their backs and also cleaning them, make the younger siblings to develop more love for them than any other person in the household. This is in line with Erikson's (1968) first stage of psychosocial theory of development which states that children between zero to 18 months develop trust when they sense that the caregiver is consistent, reliable, and dependable.

The findings from the observation process generally revealed that as the caregivers carry out their activities, they were trained to become independent and versatile. They looked for ways to easily solve their problems without waiting for their parents. For instance one of the children observed in Kishong taking care of her sibling was seen providing a solution for the junior brother who refused to eat corn fufu and okra soup the food, prepared by their mother before going to her farm. The sibling caregiver in order not to let her brother stay in hunger, improvised by roasting and pulping Irish potatoes to feed him. This example portrays an aspect of practical daily life intelligence. This resonates well with the definition of practical intelligence in terms of problem-solving in everyday contexts (Sternberg \& Wagner, 1986).

As observed in Kishong, as part of the care giving process, the caregivers taught their younger ones letters of the alphabet, colours and counting. Some of the caregivers used shaping, which is one of the principles of operant conditioning to enhance children's learning of numbers and letters (Santrock 2005). The caregivers appreciated the younger siblings' efforts to say some few letters of the Nso and English Alphabets by clapping successively until they were able to say most of the letters or develop counting skills. The findings of this research are in line with Mweru (2005) who states that older children who are already in school inform their younger siblings who are not yet in school some school related activities like counting and the letters of the Alphabets. These activities also enhance the language skills of the younger ones. The more the younger siblings interact and communicates with the caregivers the more their vocabulary increases. As the sibling caregivers sing or play with them, the younger ones imitate both their actions and words. This is in harmony with Bandura (1977) social learning theory which states that children learn through observation and imitation. This is why some younger children are able to say some words, construct meaningful sentences, and count from 1 to 10 before enrolling in the nursery schools.

It was also observed that during the care giving process, the sibling caregivers' enhanced children's positive behaviours and modified maladaptive behaviour through the use of token economy, a counselling technique propounded by the behavioural psychologists to modify behaviour (Austard, 2009). In Kishong, caregivers were observed promising the younger ones tokens (gifts) if they stopped some negative behaviour or when they wanted to promote positive behaviours. Some of the caregivers often said "if you stop entering in mud I will give you laalang (strawberry)." "Stop crying and mami will bring your sugar cane and crickets". When younger children are promised confectioneries like sweets and biscuits, they easily cease from negative behaviour or will engage in positive behaviour. Take for instance the child who refuses to eat food but does so after being promised biscuit. This shows the employment of token as a positive psychological reinforcement to induce a change in behaviour. It is an effective technique that can be used in child rearing, but should be used with caution and not too frequent so that children should not feel that any positive behaviour must be accompanied with a token or that they can only desist from negative behaviour when promised a token.

\section{CONCLUSION}

This paper was aimed at finding out the activities that characterize sibling care giving among children in Kishong. With the use of an observation, interviews and informal conversations with the sibling caregivers and parents, it was realised that sibling care giving is mostly carried out by the female children which help them to develop skills for motherhood. Some of the activities carried out by the sibling caregivers in Kishong were cooking and feeding of their younger ones, toilet training, bathing, laundry, teaching and supervision of the younger siblings in carrying out other household chores. These activities enhance basic skills like counting, thinking, cleaning, sweeping, singing and problem solving skills of both the caregivers and the younger siblings. It is a great idea for parents to assign older children especially girls to take care of their younger siblings but parents should not allow the act of care giving completely as the sole responsibility of their older children. There are times you see 
some children looking very dirty because the parents have abandon the act of laundry and bathing completely in the hands of caregivers. They should also create time to bath the children, feed them, play with them so that they children can develop an emotional tie with them. Let the children feel their parents' love. They should also supervise some of the activities carried out by the caregivers to be sure of their children's general welfare.

\section{REFERENCES}

[1] Austard, C. S. (2009). Counselling and Psychotherapy Today: Theory, Practice, and Research. New York: MCGraw Hill

[2] Bandura, A. (1977). Social Learning Theory. New York: General Learning Press.

[3] Best, D. L. (2013). African perspective on gender development. In T.Tchombe, A.B. Nsamenang, H. Keller, \& M. Fulop (Eds), Cross-cultural Psychology: An Africentric pespective (pp.159-161). Limbe: DESIGN House.

[4] Bowlby, J. (1969). Attachment and loss: (Vol.1). New York: Basic Books.

[5] Bowlby, J. (1988). A secure base: parent-child attachment and healthy human development. New York: Basic Books.

[6] Denby. R. W \& Ayala. J. (2013). Am I My Brother's Keeper: Adult Siblings Raising Younger Siblings. Journal of Human Behavior in the Social Environment, 23:193-210

[7] Erikson, E. (1950). Childhood and society. Harmondsworth: Penguin.

[8] Griffiths, D.L. \& Unger, D.G. (1994). Views about planning for the future among parents and siblings of adults with mental retardation. Family Relations, 43,221-227

[9] KLien, W., Graesch P. A. \& Izquierdo, C. (2009), Children and chores: A mixed-methods study of children's household work in Los Angeles families. Anthropology of Work Review, vol. xxx, no. 3, pp. 98-109.

[10] Kramer, L. \& Conger, K. L. (2009). What we learn from our sisters and brothers: For better for worse. New Directions for Child and Adolescent Development, 126, 1-12.

[11] Lancy, D. F. (1996). Playing on the mother ground: Cultural routines for children's development. New York: Guilford.

[12] Lancy, D. F. (2008). The Anthropology of childhood: cherubs, chattel, changelings. Cambridge: Cambridge University Press.

[13] Mweru, M. (2009). Sibling teaching during sibling caretaking. Paper presented during the conference on Child abuse and Neglect with focus on Early Childhood Development and Education,4-6 May, 2009. Addis Ababa, Ethiopia.

[14] Mweru, M. (2011). Sibling care giving and the teaching roles of children during early childhood years In Kenya. In Nsamenang, A. B., \& Tchombe, T. Handbook of African Educational Theories and Practices: A Generative Teacher Education Curriculum (pp. 247-255). Bamenda: HDRC

[15] Pruchno, R.A., Patrick, J.H., \& Burant, C.J. (1996). Aging women and their children with chronic disabilities: Perceptions of sibling involvement and effects on well-being. Family Relations, 45, 318-326.

\section{AUTHOR'S BIOGRAPHY}

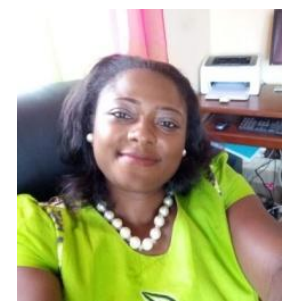

Dr. Lilian F. Wiysahnyuy is currently the chair of the Department of Guidance and Counselling, and lecturer in the Department of science of Education in the Higher Teacher Training College, The University of Bamenda in Cameroon. She is a member of the International Society for the Study of Behavioural Development (ISSBD) and Cameroon Psychology Association (CPA). Her teaching and research focus on psychology of learning, developmental psychology, early childhood development and education, school counselling and educational research methods.

Citation: Lilian F. Wiysahnyuy. "Sibling Care Giving Experiences among the Rural NSO Children of Cameroon". International Journal of Humanities Social Sciences and Education (IJHSSE), vol 5, no. 9, 2018, pp. 105-112. doi: http://dx.doi.org/10.20431/2349-0381.0509015.

Copyright: () 2018 Authors. This is an open-access article distributed under the terms of the Creative Commons Attribution License, which permits unrestricted use, distribution, and reproduction in any medium, provided the original author and source are credited. 